\title{
LA RETÓRICA DE LO NUEVO EN EL SUMARIO DE GONZALO FERNÁNDEZ DE OVIEDO
}

\author{
Francisco González Castro \\ STONY BROOK, N.Y.
}

\begin{abstract}
RESUMEN:
Esta investigación consiste en un análisis de el Sumario de Gonzalo Fernández de Oviedo. Texto surgido del imaginario de un europeo en el momento de lo que ha sido llamado alternativamente Descubrimiento o Encuentro entre dos culturas. El artículo, partiendo del texto de Oviedo, analiza como esta mirada contribuyó a la revolución epistemológica realizada en Europa en el referido momento. PALABRASCLAVE:
\end{abstract}

Literatura del Descubrimiento, Gonzalo Fernández de Oviedo, Epistemologia.

I

El encuentro fortuito, imprevisto, con algo desconocido se desarrolla, de la manera más simplificada, en dos fases: un primer asombro por la peculiaridad de lo hallado y una posterior conciencia de asimilación. De este modo, la solución final se debate en un proceso dialéctico que proyecta las múltiples posibilidades de tratamiento del nuevo objeto o de la nueva realidad. Imaginemos lo dicho anteriormente, pero con respecto a un continente, con civilizaciones dispares y formas muy distintas de cultura. Un acontecimiento de tal índole se hizo realidad en 1492, en el escenario del que algunos han llamado "descubrimiento de América", y otros han preferido denominar "encuentro entre 
dos mundos". Fue una oportunidad histórica de grandes repercusiones en la cultura, en la sociedad y en el pensamiento de ambos lados del Atlántico. La exploración del nuevo mundo desplegó, para bien y para mal, todas las formas posibles de relación humana. En medio de esta diversidad de relaciones, el presente estudio quiere detenerse en el encuentro con la naturaleza de Las Indias: sus habitantes, sus animales, sus plantas. La razón es que de ese conocimiento surge la necesidad de explicar lo raro y extraordinario en el ámbito real de América. Para ello, se ha escogido en forma de muestra una obra titulada Sumario de la natural historia de Las Indias (1526) de Gonzalo Fernández de Oviedo. de la natural historia de Las Indias (1526) de Gor el autor, el Sumario permitirá analizar un punto de vista ante la novedad, que siempre remitirá a los puntos de vista de los demás protagonistas del acercamiento a América. La obra de Fernández de Oviedo se plantea como un informe de las cosas vistas en las nuevas tierras. Es un discurso explicativo de un europeo en el que se mezcla el saber establecido por la tradición con evidencias, aportadas por la realidad americana, que contradicen esa tradición. Por eso resulta interesante abordar los presupuestos que pudieron determinar la de Oviedo y todas aquellas primeras viciones de América.

\section{Los Antecedentes (La Tradición).}

La visión del Nuevo Mundo estuvo condicionada por la mentalidad europea de la época y por una serie de ideas asumidas que se tenían como verdaderas fuentes de conocimiento. En primer lugar, la concepción del mundo en la antigüedad se definía en el concepto de Orbis Terrarum, que se refería a la porción de tierra habitada por el hombre (situada en el hemisferio norte). No se descartaba que hubiese otras porciones de tierra, pero debían estar deshabitadas. Es más, sólo la zona templada del Orbis Terrarum era la apta para la vida humana. Desde estos presupuestos, ni se preveía la existencia de una gran masa continental. Añádase a esto la concepción cristiana del mundo; concepción unitaria que rechazaba la existencia de otros mundos. Por tanto, todos los principios de autoridad corrían peligro en caso de plantearse alguna posibilidad contraria a las ideas preestablecidas.

En el siglo XII los primeros viajeros se introdujeron en la enigmática Asia. Marco Polo viaj6 a los dominios del Gran Khan en 1271. Se propagaron los relatos fabulosos sobre Oriente. Noticias de seres fantásticos, aberrantes y monstruosos llegaron hasta Europa. Según Marco Polo, en el reino de Pasei había unicornios; en el reino de Dragoian se practicaba el canibalismo. En la isla de Andaman había hombres con cabeza de perro. El europeo situaba en los lugares más recónditos las figuras que representaban la amenaza o el miedo colectivo.

Si fascinante resulta el relato de Marco Polo, no menos lo es el personaje del Preste Juan, del que se hace mención en el libro del viajero veneciano. Las noticias que circulaban en Europa sobre el Preste Juan y sus dominios contribuyeron especialmente a la formación de la idea europea de Oriente. Ya desde fines del siglo XI se habla de este mítico personaje. El Bestiario recoge algunas palabras suyas sobre su tierra:

Sabed también que en nuestra tierra están los sagitarios, que tienen forma humana de la cintura para arriba, y son caballos hacia abajo. Llevan arcos y flechas en las manos, disparan con más fuerza que cualquier otra especie de gentes, y comen carne cruda. Algunos de nuestra corte los capturan y los tienen encadenados; las gentes acuden a verlos como un gran prodicio.'

No hay que olvidar un hecho de vital importancia: la primera visión de América proporcionada por Colón estuvo absolutamente mediatizada por los relatos de Marco Polo. Nos habla el Almirante en su Diario de la existencia de cíclopes, caníbales con hocico de perro, sirenas y hombres con cola:

Entendió también que lexos de allí avía hombres de un ojo y otros con hocicos de perros que comían hombres, y que en tomando a uno lo degollavan y bebían la sangre y cortavan su natura. ${ }^{2}$

Además, Colón llegó a sostener que el Paraíso terrenal se hallaba en América del Sur. Todo este conjunto de ideas contribuyó a la formación de una primera y duradera imagen de América, que sobrepasa la realidad a través de un proceso de invención, tal y como ha señalado Edmundo O'Gorman. ${ }^{3}$

A esta confluencia de creencias, debemos añadir la extraordinaria difusión durante toda la Edad Media de los bestiarios, cuyas páginas mostraban un mundo poblado por bestias fabulosas y extrañas, híbridos imposibles

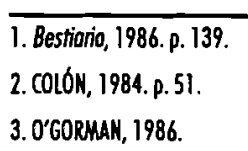


enmarcados en una naturaleza estridente e indómita; y las referencias bíblicas (Levítico) que nombran a seres como el grifo, mezcla de león y águila. ¿Cómo influyeron todos estos aspectos del conocimiento en un hombre como Gonzalo Fernández de Oviedo, situado ante una novedad de la que hay que hablar? Esta interrogante, que se presenta como parte fundamental de este trabajo, subyace en la obra del autor español y llega a concretarse en los conflictos epistemológicos que surgen a lo largo de las páginas del Sumario.

\section{EI Sumario de la natural historia de las Indias.}

Aunque no se dice explícitamente, Oviedo tenía muy presente la tradición de lo exótico difundida por todas las fuentes señaladas anteriormente. No obstante, desde el primer momento se aprecia una voluntad de racionalización del objeto de estudio. Recordemos cómo tuvo lugar el primer acercamiento a lo nuevo. El objetivo de Colón era encontrar una ruta occidental hacia Las Indias. Su obsesión después de llegar a las nuevas tierras fue verificar sus hipótesis y encontrar pruebas convincentes de que había alcanzado el Extremo Oriente. Oviedo, sin embargo, parte en el Sumario desde una conciencia de novedad que hay que explicar: "....La novedad de lo que quiero decir, que es el fin con que a esto me muevo; lo cual digo y escribo por tanta verdad..."4

En efecto, el planteamiento del Sumario es el criterio de veracidad. No olvidemos que el libro está dirigido al emperador Carlos, y César no quiere fábulas. Por otro lado, la influencia erasmista favorecí un tipo de literatura verdadera y provechosa ajustada al principio de verosimilitud. Se descarta, por tanto, una recreación fantástica, ya que va en contra de lo visto y vivido. La intención de Fernández de Oviedo se ajusta más al espíritu renacentista de observar, comprender y divulgar: "Porque con menos atención las miran y consideran que el que por natural inclinación, como yo, ha deseado saberlas."

En resumen, el Sumario se plantea desde sus primeras páginas como una historia presidida por el criterio de verdad y la relación fidedigna apoyada en el recuerdo de lo visto. Todo esto siguiendo de cerca el modelo de Plinio. La lengua elegida es una lengua romance que, por las circustancias políticas, es de gran alcance.

4. Fernóndez de Oviedo, 1963. p. 21

5. Ibidem. p. 20
El itinerario marcado en el Sumario es el siguiente: camino de navegacion, habitantes, animales terrestres, aves, ríos y fuentes y mares, pescados, plantas, hierbas, productos de la tierra y ritos y ceremonias de aquella gente. Se comienza por la ruta que siguió Colon (navegación), pero no se llega a Asia, sino a algo de lo que no se tenía conocimiento previo: "Todo esto es mejor remitirlo a las cartas de navegar y cosmografía nueva, la cual ignorada de Tolomeo y los antiguos, ninguna cosa de ella hablaron"'.

Oviedo parte de una premisa muy concreta: la ciencia del Viejo Mundo no preveía la existencia de América. Esta es la conciencia de novedad. He aquí la primera gran diferencia con el Almirante. Esta conciencia de lo nuevo lleva a la necesidad de explicación, porque es diferente a todo lo conocido (incluido el conocimiento suministrado por los bestiarios y los relatos fantásticos). Por tanto, la autoridad de los clásicos resulta inadecuada y superable:

Ignorantes de todo los antiguos, decían ser inhabitable naturalmente la dicha zona tórida y equinocial línea. Todo esto depongo y afirmo como testigo de vista, y se me puede mejor creer que a los que por conjeturas, sin lo ver, tenían contraria opinión.'

Plinio es el modelo declarado en el Sumario. Oviedo es consciente de la ejemplaridad del maestro, pero también de la superabilidad de la autoridad clásica. Tomemos como ejemplo la descripción del tiburón que aparece en el Sumario: "Es pescado de cuero, como los cazones y tollos; los cuales, y el dicho tiburón, paren otros sus semejantes, vivos; y esto digo porque Plinio ninguno de aquestos tres puso en el número de los pescados que dice en su Historia Natural que paren"».

Autoridad clásica superable pero no despreciable por inútil. El autor está inserto en las coordenadas epistemológicas del Viejo Mundo, y las necesita precisamente para reivindicar la especifidad americana. El procedimiento de análisis de la nueva naturaleza, caracterizada en un principio por la confusión, se puede esquematizar en dos estrategias:

1. Dada esta situación, Fernández de Oviedo se erige en autoridad como testigo visual. Todo su discurso está valorizado por el yo, la propia
6. Ibidem. p. 22.

7. bidem. p. 42.

8. Ibidem. p. 120. 
experiencia.

2. Admitidas las dimensiones no europeas de la nueva naturaleza, se opta por una aproximación al objeto de estudio de corte empirista: observar, describir y razonar.

En la aplicación de estas tres fases (observación, descripción y razonamiento) surge de inmediato una polémica entre lo evidente (lo que se tiene ante los ojos) y su ajuste al marco de fenómenos conocidos para una mentalidad europea. El proceso se desarolla según la siguiente dinámica: Oviedo posee unas coordenadas epistemológicas sustentadas por las autoridades reconocidas en el Viejo Mundo. Se aplican al Nuevo Mundo con el consiguiente desajuste referencial. Ante esta situación, Oviedo se erige en autoridad. Ilustrativa en este sentido resulta la descripción que aparece en el Sumario de una clase de árboles':

Unos árboles hay en la isla Española espinosos, que al parecer ningún árbol ni planta se podría ver de más salvajez ni tan feo, y según la manera de ellos, yo no me sabría determinar ni decir si son árboles o plantas... Finalmente es de manera que es dificultoso escribir su forma, y para darse a entender sería necesario pintarse, para que por medio de la vista se comprendiese lo que la lengua falta en esta parte. ${ }^{10}$

El desajuste referencial absoluto está provocado en este caso por la falta de un término lingüístico que exprese el objeto. La filosofía latente en Oviedo es la del lenguaje como configurador y ordenador del mundo; el lenguaje clasifica y fragmenta la inaccesible totalidad. Si algo existe, debe ser nombrado. Ese es el primer paso de la asimilación de la nueva realidad: la comprensión de la realidad supone su nombramiento. De este modo, la masividad del primer momento se individualiza para, a continuación, incluirla en el espectro global de visión de mundo. Como vimos en el ejemplo anterior, Oviedo se enfrenta con la dificultad de lo inefable. Para romper esta barrera, se emplean varios métodos:

a. Nombramiento por medio de la incorporación de términos aborígenes: "Hay otra manera de pan que se llama cazabi, que se hace de unas

9. Juan Boutisto Avolle-Asce anota, en lo edición del Sumorio ufilizodo en el presente estudio, que dicho árbol es, según álverez López, lo Opuntio triocontho.

10. 16idem. p. 108. raíces de una planta que los indios llaman yuca"ll.

b. Propiedad en la designación: "Los cristianos que en Tierra Firme andan llaman danta a un animal que los indios le nombran beorí, a causa que los cueros de estos animales son muy gruesos, pero no son dantas. E así han dado este nombre de danta al beorí tan impropiamente como ochi el tigre."'2

c. Explicación por similitud y contraste. Referencia a lo que se encuentra o no se encuentra en España: "El oso hormiguero es cuasi a manera de oso en el pelo, y no tiene cola; es menor que los osos de España, y cuasi de aquella facción, excepto que el hocico tienen más largo, y es de muy poca vista"13.

Los métodos anteriormente descritos son estrategias del conocimiento para asimilar una realidad que resulta básicamente nueva. Esta necesidad de entender procura distanciarse, pero nunca desligarse, de los esquemas cognitivos habituales en un entorno determinado, en este caso, el europeo renacentista. Dichos esquemas pueden interferir, y de hecho es así, entre la conciencia y el objeto. Oviedo hace patente el conflicto entre lo admitido lo autorizado y lo que se tiene ante los ojos cuando habla, por ejemplo, del jaguar, identificado con el tigre, mucho más familiar para los españoles. advierte Oviedo que al tigre le viene su nombre del griego, "y tiguer en griego quiere decir saeta"14. Esta puntualización remite a un saber asumido que podemos ver transcrito en los bestiarios: "Tigris, el tigre, toma su nombre de su veloz carrera; pues los persas, medos y griegos solían llamar a la flecha “tygris"... Este animal puede distinguirse por su rapidez extraordinaria." 15

No obstante, Oviedo sospecha, gracias a la observación, que el felino de Las Indias no puede identificarse con el tigre tradicional: "Pero yo no me determino si son tigres, viendo lo que se escribe de la ligereza del tigre y lo que se ve de la torpeza de aquestos tigres llamados en Las Indias"16.

El Bestiario, término general que agrupa a las distintas colecciones de animales reales o quiméricos, es una importante fuente tradicional que se filtra a tavés de las páginas del Sumario. Como forma de conocimiento medieval
11. bidem. p. 29.
12. Ibidem. p. 59 .
13. 16 idem. p. 61 .
14. Ibidem. p. 55.
15. Bestiorio, 1986. p. 9.
16. FERNÁNDEZ OE OVIEDO, op. cit. p. 56 
que desplegaba su propia visión de mundo, resulta particularmente interesante ver en qué medida condiciona la escritura y la ideología de la obra que nos ocupa.

\section{El Sumario y los bestiarios.}

Los bestiarios tuvieron una amplia difusión en la Edad Media y estuvieron muy arraigados en el saber y la mentalidad del hombre medieval y renacentista. Los bestiarios plasman las inquietudes y desazones que se apoderaron del hombre deseoso de explorar lo desconocido y lo misterioso. Enlazan directamente con la mitología grecolatina. La naturaleza representada en estos libros se caracteriza por su dimensión fantástica y negativa. En efecto, la fauna, sobre todo en el bestiario telúrico, se nos aparece híbrida, estridente, infernal e indómita. El animal es lo impenetrable y lo extraño por excelencia. Estas bestias fabulosas habitan lugares exóticos como la India, Etiopía, Oriente. Dice el Bestiario: "Existe un animal llamado elefante, que carece de deseo de copular... Si uno de ellos desea criar, se encamina a Oriente, hacia el Paraíso"ll.

Como bien se puede apreciar, la descripcion anterior contiene un elemento estridente (carece de deseo de copular) y una creencia asumida (el Paraíso está en Oriente). Los animales son definidos principalmente por su singularidad; es decir, cada uno tiene una propiedad que resulta prodigiosa $o$ misteriosa: "La serra es un animal marino de extraordinario tamaño, que posee alas y plumas de asombrosas proporciones"18.

Esta condición extraña de las especies produce un efecto de estupor ante una naturaleza completamente ajena al individuo y fuera de la concepción del cosmos armonioso que empezaba a prevalecer en el Renacimiento.

La tradición de los bestiarios fluye por varias partes del Sumario. Desde el punto de vista formal, Oviedo nos ofrece una sucesión de animales y plantas a modo de estampas, aludiendo a sus características más destacables. También los bestiarios nos presentaban una colección de especies estáticas definidas por su peculiaridad; pero Oviedo necesita mostrar todo en segmentos discretos para facilitar la aprehensión de lo nuevo. Su objetivo es extender el

17. Bestiario, 1986. p. 3.

18. 1bidem. p. 70. dominio de la Historia Natural con la integración de las criaturas americanas. Así, se puede describir a los seres más raros con un patente afán de análisis desmitificador. Remitámonos de nuevo al Sumario cuando describe al armadillo:

Los encubertados son animales mucho de ver, y muy extraños a la vista de los cristianos, y muy diferentes a todos los que se han dicho o visto en España... Es de la facción y hechura ni más ni menos que un caballo encubertado, con sus costaneras y coplón... Yo los he comido muchas veces, y son mejores que cabritos en el sabor."

Tres fases podemos distinguir en esta definición: en primer lugar, la extrañeza ante animal tan raro. Luego, la explicación en términos que establezcan una semejanza con algo ya conocido (caballo encubertado) y, por último, la desmitificación a través e la referencia a la calidad alimenticia. Nótese que en este ejemplo concreto el nombre de "encubertado" le fue asignado a este animal por su caparazón protector, el cual recordaba a las armaduras que servían de defensa contra las agresiones del enemigo. Mientras que los bestiarios hacen hincapié en lo discordante, Oviedo trata de relacionar lo nuevo y lo viejo mediante un razonamiento conciliador. De este modo, no resulta tan sorprendente encontrar a un animal de la hechura del encubertado, ya que los mismos españoles han desarrollado una técnica muy similar para proteger a sus caballos. Todo pasa por un proceso de normalización. Se intenta eliminar el estereotipo de la aberración natural y moral que fue difundida por las historias fantásticas de los primeros navegantes europeos.

Además de la disposición formal, Oviedo emplea procedimientos descriptivos muy parecidos a los de los bestiarios. Las iguanas son como una especie de sierpes que a la vista resultan espantosas. La cola es como la de un lagarto; su tamaño es mayor que el de un conejo y tiene uñas de pájaro. Asimismo, no se sabe si pertenece a la tierra $o$ al agua. Las bestias fabulosas se caracterizaban por la mezcla de rasgos dispares. Las fronteras entre los reinos eran confusas. El caso más extremo que se puede encontrar en el Bestiario es la hormiga-león, con "los miembros delanteros de un león, y las partes traseras de hormiga" Sin embargo, la intención de Oviedo no es provocar el asombro con estos procedimientos, sino proyectar una imagen más nítida de un ser viviente. Por eso se afana en describir minuciosamente el aspecto y las costumbres del animal;

\section{FERNÁNOEZ OE OVIEDO, op. cit. p. 63-64.}

20. Bestiorio, 1986. p. 172. 
puntualizando que, a pesar de su visión espantosa, "no hacen mal" y que "la carne... es tan buena o mejor que la del conejo" ${ }^{\prime \prime l}$. Estas últimas palabras destruyen cualquier intento de mitificación. El engullimiento pone de manifiesto la actitud antropocéntrica frente a la naturaleza. Se han invertido los patrones: ya no es el animal el que engulle al hombre. De este modo, el efecto conseguido es justamente el contrario al de los bestiarios.

El conocimiento que transmitían las colecciones de animales fabulosos también puede descubrirse en el Sumario. Cuando la observación no puede dar cuenta de los fenómenos, se busca la explicación más satisfactoria. Esto es lo que acontece con el perezoso, denominado en la época de Oviedo "perico ligero". Este animal llama la atención del autor porque no llega a descubrir sus hábitos alimenticios: "Yo lo he tenido en mi casa, y lo que supe comprehender de este animal es que se debe mantener del aire"'l. Esta conclusión no resulta aberrante pra la época, ya que no es la primera vez que se dice que un animal se alimente del aire. Según los bestiarios, el camaleón ni come ni bebe, sino que vive del aire que aspira.

Muchos de los bestiarios fueron compuestos con una intención puramente moralizante. La descripción de los animales servía para formular una interpretación alegórica de las Escrituras. Las criaturas se convierten en símbolos del dogma cristiano para ilustrar a los fieles. Sirva de ejemplo el unicornio:"Que este animal tenga un solo cuerno en la cabeza, representa al Salvador"'s. No es éste el planteamiento primario del Sumario. Oviedo pretende simplemente dar a conocer al Emperador la diversidad de sus nuevos reinos. Sin embargo, alguna vez se desprende en la obra de Fernández de Oviedo la disgresion doctrinal a la manera de los bestiarios, pero ocurre en ocasiones muy precisas y a modo de conclusión. Ya casi al final del libro, se nos habla de los peces voladores y sus depredadores tanto en el agua como en el aire:

De manera que ni arriba ni abajo tenían seguridad; y este mismo peligro tienen los hombres en las cosas de esta vida mortal, que ningún seguro hay para el alto y bajo estado de la tierra; y esto sólo debería bastar para que los hombres se acuerden de aquella segura holganza que tiene Dios aparejada a quien le ama. ${ }^{24}$
Se trata de una pequeña dosis de adoctrinamiento para recordar el ámbito cristiano en el que se inserta el libro.

La naturaleza no es un caos sin razón ni concierto. Esta es la idea que subyace en el Sumario. Oviedo, como hombre de su época, conocía la tradición de la naturaleza misteriosa y estridente, pero también participaba de la disposición del hombre renacentista: las cosas tienen una explicación aunque se muestren aparentemente inasequibles a la razón. De ahí, el afán de observación y razonamiento. Añádase también la idea de armonía cósmica transmitida por el neoplatonismo y la visión analógica del mundo vigentes en el Renacimiento. $\mathrm{Si}$ la naturaleza es una manifestación gloriosa y magnífica de Dios no puede existir nada discordante con la obra divina y si hay algo diferente, es porque ha sido previsto por el Hacedor. En este caso, el hombre debe intentar conocer y entender, para mayor admiración, todas esas manifestaciones.

El descubrimiento de América supuso un replanteamiento y una reflexión sobre creencias muy asumidas en Europa. La realidad de una nueva naturaleza, y de otros grupos humanos, exigió una toma de posición ante la novedad. Fernández de Oviedo optó por una aproximación racional del fenómeno. El tipo de discurso que inaugura el autor del Sumario es el signo de ese lento cambio de mentalidad que empieza a manifestarse en el ámbito europeo. Frente al pensamiento medieval, en el que la ciencia se fundamenta en el principio de autoridad, el pensamiento renacentista establece los principios científicos a partir de la observación de los hechos. Con la crisis del principio de autoridad y el conflicto de fuentes, comienza el discurso de la ciencia moderna. Fernández de Oviedo se integra en esta corriente junto con figuras tan representativas como Copérnico (1473-1543), a quien debemos el impactante tratado titulado De revolutionibus orbium coelestium (concluido en 1530); y Vesalio (1514-1564), que publicó el primer tratado verdaderamente científico de anatomía humana: De corporis humani fabrica. Todos estos nombres tipifican la nueva cosmología basada en la observación directa y en el razonamiento. En el marco de esta revolución epistemológica, el análisis de la nueva realidad americana fue un factor que contribuyó decisivamente a la transformación de los presupuestos de la vieja ciencia y de la imaginación europea.

21. FERNÁNDEZ DE OVIEDO, op. cit. p. 32.

22. Ibidem. p. 23.

23. Bestiario, 1986. p. 148.

24. FERNÁNDEZ DE OVIEDO, op. cit. p. 123. 
Este trabalho é uma análise do Sumario de Gonzalo Fernández de Oviedo. Texto surgido do imaginário de um europeu no momento que tem sido chamado alternativamente Descoberta ou Encontro entre duas culturas. $O$ artigo, partindo do texto de Oviedo, analisa como este trabalho contribuiu para a revolução epistemológica originada, nessa época, na Europa.

PALAVRASCHAVE:

Literatura do Descobrimento, Gonzalo Fernández de Oviedo, Epistemologia.

\section{REEERÊNCAS BIBLIOGRÁFICAS}

AVALLF-AREE, J.B. Los memorias de Gonzolo Fernóndez de Oviedo. North Corolino: Chopel Hill, 1974

ALVAREZ LOPEZ, E. Lo historia noturol en Fernóndez de Oviedo. Revisto de Indios. Bogotó, XVII, p. 445-467, 1957.

Bestiario medieval. Madrid: Sirvelo, 1986.

coloN, Gistobol. Textos y documentos completos. Morid: Alionzo, 1984.

FERAANDEZ DE OVEDO, 6. Sumario de la natural historio de Los Indias. Solomonco: Anoyo, 1963.

LAIN ÉNTRALGO, P. Fernóndez de Oviedo ontel lo noturadezo del Huevo Mundo. Estudios sobre literofura y arte dedicados al profesor Emilio Orozco Draz. Universidad de Gronoda, p. 215-230, 1979.

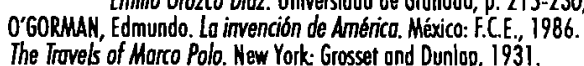

\section{FRAGMENTOS DE UMA HISTÓRIA DE TRAVESSIAS: TRADUÇÃO E (RE)CRIAÇÃO NA PÓS-MODERNIDADE BRASILEIRA E HISPANO-AMERICANA}

Else Ribeiro Pires Vieira

$U F M G$

Travessia perigosa, mas é a da vida...

Guimarães Rosa

Não há lua inteira, consumada nos

espelhos das águas que se movem

D.H. Lawrence

... "becoming" as a general principle. Deleuze calls the phenomenon "double capture".... an asymmetrical takingon of new properties... "Becoming" is not therefore a relation of opposition, of either $x$ or $y$ ", but rather a matter of encounter, of capture, of $x$ and $y$.

Jenkins

\section{RESUMO:}

Situando-se no espaço "movimentante" associável à intensificação da tradução na pós-modernidade brasileira e hispano-americana, um fenômeno que remonta à própria modernidade, o texto analisa a metalinguagem daqueles tradutores latino-americanos que a teorizaram como recriação. Desvios, transformações, mutações, suplementos 